\title{
Agenesis of Third Molars and Its Aetiology in Tamil Nadu Population
}

Saravakumar ${ }^{1}$ and Sosa George ${ }^{2}$

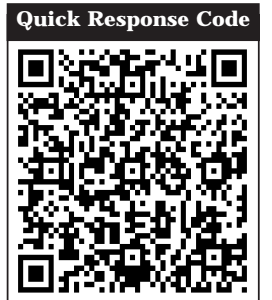

doi: $10.5866 / 2015.7 .10165$

${ }^{1}$ Senior Lecturer

Department of Anatomy

Saveetha Dental College,

Chennai, Tamilnadu.

24th yr BDS student

Saveetha Dental College,

Chennai, Tamilnadu

\section{Article Info:}

Received: J uly 9, 2015

Review Completed: August 7, 2015

Accepted: September 8, 2015

Available Online: J uly, 2015 (www.nacd.in)

(C) NAD, 2015 - All rights reserved

\section{Email for correspondence:}

sosageorge.work@gmail.com

\begin{abstract}
:
BACKGROUND: Third molars are the last teeth to erupt in the oral cavity and are something of an enigma for a dentist. As a continuous process of evolution, the number of cases of missing third molars is seemed to be increasing. Updating the knowledge on third mol ar eruption status would be hel pful in clinical practice.

AIMS: To understand the prevalence and probable aetiology of third molar agenesis in Tamil Nadu population and to find out the possible causes of the same.

MATERIALS AND METHODS: A total of 100 patients between the age of 15 and 35 years who reported to clinic 5 of Saveetha Dental Hospital were chosen randomly for the study. At first the third mol ars were examined visually. Those with unerupted teeth were subjected to radiographic examination. An OPG was taken for all the subjects in this group. All the subjects were handed a questionnaire. The patients were questioned for their dietary and the presence of third molars in their parents.

RESULTS: $63 \%$ of the participants had at least one unerupted third molar. $6 \%$ of the participants showed agenesis of third molar. Agenesis showed a maxillary predilection. All the subjects who showed agenesis were females.

CONCLUSION : Thereseems to befamilial inheritance of agenesis. In some people who reported with congenitally absent third molars, agenesis of other permeant teeth were also seen. Further study is required to find out if there are any associated genes which may be responsible for agenesis.
\end{abstract}

Key words: Third molar, Agenesis, Unerupted

\section{INTRODUCTION:}

Third molars are the last teeth to erupt in the oral cavity and are something of an enigma for a dentist. Agenesis is the congenital absence of at least one permanent tooth. The eruption or impaction of third molars is most often associated with pain, swelling and many other problems for the patient. In these conditions the problematic third molar is extracted and sometimes the procedure may be accompanied by post-extraction complications such as bleeding and dry socket. Third molars are the teeth that are most associated with impaction. The study on third molars not only interest dental professionals but also specialists in anthropology, genetics etc. this is because third molars are found to be important in understanding the process of 
evolution. Many times third molars are not involved in occlusion and mastication. As a continuous process of evolution, the number of cases of missing third molars is seemed to be increasing.

U pdating the knowledge on the status of third molars would be helpful in clinical practice. This study is aimed at understanding the incidence of agenesis of third molars in Tamil Nadu population and the probable causes of the same.

\section{MATERIALS AND METHODS:}

A total of 100 patients between the age of 15 and 35 years who reported to clinic 5 of Saveetha Dental Hospital werechosen randomly for the study. The patients came from different places of Tamil $\mathrm{N}$ adu. Hence the sample size can be considered to be representing Tamil Nadu population. Those who had the history of previous extraction of third molars and all who refused to give consent were excluded from the study.

At first the third molars were examined visually. All subjects were examined clinically for the status of third molar and were classified into completely erupted and unerupted. Group A contained people with completely erupted 4 third molars. Group B contained subjects who had at least one unerupted third molar. Those with unerupted teeth were subjected to radiographic examination. An OPG was taken for all the subjects in group B.

All the subjects were handed a questionnaire. The patients were questioned for their dietary habits and the frequency in which they consume nonvegetarian food, fibre rich food and soft food. Subjects were also questioned on the presence off third molars in their parents.

\section{RESULTS:}

Out of 100 subjects, 68 were male and 32 were female. There were 37 subjects in group $A$ and 63 subjects in group B. $42.1 \%$ of the subjects in group $B$ had at least 1 unerupted maxillary third molar. Whereas the percentage of subjects with at least one unerupted mandibular third molar in group $B$ was found to be $93.75 \%$. The graph 1 shows the group B subjects based on the number of unerupted third molars in upper and lower arch separately.
$31.25 \%$ of the subjects in group B had one unerupted third molar. $43.75 \%$ had two unerupted third molars. The percentage of subjects in group $B$ with three and four unerupted third molars was $14 \%$ and $9.3 \%$ respectively.

Upon analysing OPG, it was found that $9.4 \%$ $(n=6)$ of the subjects in group $B$ had at least one congenitally missing third molar. Out of 6 subjects, one had two congenitally absent maxillary third molars. Five subjects had single congenitally missing maxillary third molar. Two subjects had missing single mandibular third molar. All the subjects who had congenital absence of third molars were female.

When questioned on the prevalence of third molar unration among their parents, four of the subjects with congenital absence of third molars reported that their mothers had congenitally missing third molar. Two of the subjects were not sure about the status of third molars in parents.

When questioned on the dietary habits of the individuals. Four of the subjects with congenital absence of third molars are frequent nonvegetarians, one of them is occasional nonvegetarian and another person is a pure vegetarian.

\section{DISCUSSION:}

Third molars which are commonly called as wisdom teeth are the last set of teeth to erupt in the oral cavity. The average age of eruption of third molars is $17-20$ years. For some individuals this eruption happens at a much later stage and in many cases eruption does not happen at all. The pain, swelling and complications associated with the eruption and extraction of third molars has made it a subject of interest to dentists. Diet, extend of usage of masticatory system, genetic and racial predilection are all factors that influence the jaw and tooth size and structure.

In the present study 100 random subjects between the age of 15 and 35 were chosen from among the patients who reported to Saveetha dental hospital. $63 \%$ of the subjects had at least one unerupted third molar. It was found that $6 \%$ of the subjects had at least one congenitally missing third molar. All the subjects who had congenitally missing 


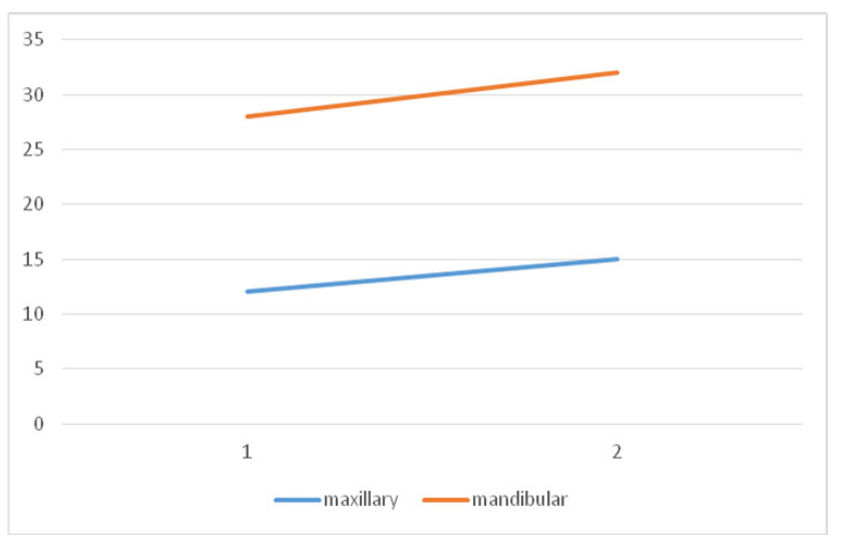

Graph 1: Graph 1 shows group B subjects based on the number of unerupted third molars in upper and lower arch separately.

third molars were found to be female. This is suggestive of a female predilection to the same. $5 \%$ of the subjects had at least one congenitally absent maxillary third molar which shows the maxillary predilection of agenesis. Dietary influence was found to be negligible. Four percent of the subjects had parents who also had unerupted third molars. The incidence of agenesis in those parents could not be analysed through OPGs. If they have agenesis, then it is suggestive of hereditary factors playing a role in agenesis.

A study conducted in Haryana showed that there is $35.4 \%$ incidence of third molar agenesis. Agenesis of maxillary third molar was found to be more significant in the study. ${ }^{1}$ A study on the patterns of third molar agenesis and associated dental anomalies in an orthodontic population found that permanent tooth agenesis is frequently associated with third molar agenesis. ${ }^{2}$ A study conducted among Li ibyan students showed that there is maxillary as well as female predilection for agenesis of third molars. ${ }^{3}$ A study conducted in Punjab showed that $26 \%$ of the subjects had missing third molars. ${ }^{4}$ Agenesis of third molars are sometimes associated with congenital absence of other permanent teeth also. Lateral incisors, second premolars, central incisors, second permanent molars, canines and first premolars are the teeth which show associated agenesis in the order of their prevalence. The male to female ratio of third molar agenesis was proposed as 3:2. ${ }^{5}$ A study conducted in Belgaum, Karnataka showed that 3.3\% of the subjects had agenesis of all the third molar. ${ }^{6}$ In a study conducted in Nepal the prevalence of third molar agenesis was found to be $50.34 \% .^{7}$ Study conducted in Czech population showed that the agenesis of third molars is $22.5 \%$ and there is male predilection for agenesis. ${ }^{8}$

\section{CONCLUSION:}

Third molar agenesis is prevalent among the population today. It shows maxillary predilection and also female predilection. There seems to be familial inheritance of agenesis. In some people who reported with congenitally absent third molars, agenesis of other permeant teeth were also seen. Further study is required to find out if there are any associated genes which may be responsible for agenesis.

\section{REFERENCES:}

1. Bhawandeep Kaur, Soheyl Sheikh, Shambulingappa Pallagatti. Radiographic assessment of agenesis of third molars and para-radicular third molar radiolucencies in population of age group 18-25 years old - a radiographic survey. Arch Oral Res 2012; 8:13-18

2. Celikoglu M, Bayram M, Nur M. Patterns of third-molar agenesis and associated dental anomalies in an orthodontic population. AmJ Orthod Dentofacial Orthop 2011; 140:856860

3. Sujata Byahatti, Mohammed SH. Ingafou. Prevalence of eruption status of third molars in Libyan students. Dent Res J 2012; 9:152-157.

4. Bansal S, Gupta K, Garg S, Srivastava SC. Frequency of impacted and missing third molars among orthodontic patients in the population of Punjab. Indian J Oral Sci 2012; 3:24-27

5 Sivakumar Nuvvula, Kiranmayi M, Shilpa G, Nirmala SVSG. Hypohyperdontia: Agenesis of three third molars and mandibular centrals associated with midline supernumerary tooth in mandible. Contemp Clin Dent 2010; 1:136-141.

6. Sujata M Byahatti, Ramakant Nayak, Bhushan J ayade. Eruption status of third molars in south I ndian city. J ournal of Indian Academy of Oral Medicine and Radiology 2011; 23:328-332

7. Chandan Upadhyaya, Bhoj Raj Adhikari, Dashrath Kafle, Manoj Humagain. Agenesis of Third Molars in Orthodontic Patients attending Dhulikhel Hospital. OrthodonticJ ournal of Nepal 2012; 2:32-35.

8. Rozkovcova E1, Markova M, Lanik J , Zvarova J. Agenesis of third molars in young Czech population. Prague Med Rep 2004; 105:35-52. 